\title{
INTESTINAL OBSTRUCTION IN PAEDIATRIC AGE GROUP DUE TO FOREIGN BODY INGESTION
}

Pankaj Kumar Saunakiya1, Satendra Rajput², Santosh Kumar Saroj33, Santvir Singh4, Rajkumar Verma ${ }^{5}$

${ }^{1}$ Lecturer, Department of Surgery, MLB Medical College, Jhansi, U. P.

${ }^{2}$ Lecturer, Department of Surgery, MLB Medical College, Jhansi, U. P.

${ }^{3}$ Senior Resident, Department of Surgery, MLB Medical College, Jhansi, U. P.

${ }^{4}$ Senior Resident, Department of Surgery, MLB Medical College, Jhansi, U. P.

${ }^{5}$ Assistant Professor, Department of Surgery, MLB Medical College, Jhansi, U. P.

HOW TO CITE THIS ARTICLE: Saunakiya PK, Rajput S, Saroj SK, et al. Intestinal obstruction in paediatric age group due to foreign body ingestion. J. Evolution Med. Dent. Sci. 2018;7(04):548-549, DOI: 10.14260/jemds/2018/123

\section{PRESENTATION OF CASE}

An eight-year-old girl presented with chief complaints of abdominal pain associated with abdominal distension and paucity of faeces and flatus for four days. Pain was colicky in nature, mostly involving lower part of the abdomen. Patient gave a past history of ingestion of multiple foreign bodies in the form of small marbles.(1) On physical examination, her abdomen was distended. Guarding and rigidity were absent and crackling sound was present over the lower part of her abdomen. Digital rectal examination revealed some marbles in the anal canal.

\section{CLINICAL DIAGNOSIS}

Clinically, the case was diagnosed as subacute intestinal obstruction caused by foreign body ingestion.

\section{DIFFERENTIAL DIAGNOSIS}

Differential diagnosis of subacute intestinal obstruction can be made by band, volvulus, intussusceptions, malformation and foreign body ingestion.

\section{PATHOLOGICAL AND RADIOLOGICAL DISCUSSION}

Laboratory studies showed Hg- 9.4 mg\%, TLC- 7500, platelet count $80000 / \mathrm{mm}^{3}$. Serum albumin- $2.5 \mathrm{gm} / \mathrm{dL}$. Blood urea,

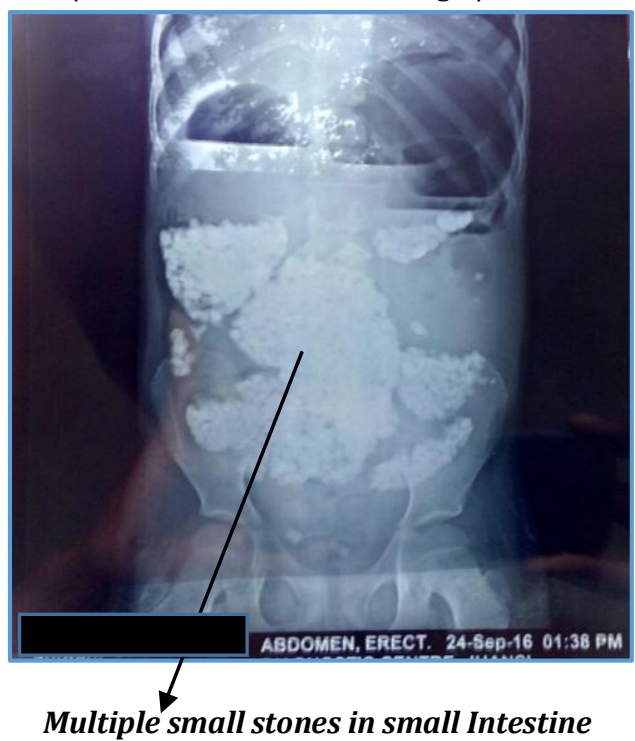

'Financial or Other Competing Interest': None.

Submission 01-09-2017, Peer Review 06-01-2018,

Acceptance 13-01-2018, Published 22-01-2018.

Corresponding Author:

Dr. Pankaj Kumar Saunakiya,

PR-14, MLB Medical College Campus,

Jhansi.

E-mail: drpankajsaunakiya@gmail.com

DOI: $10.14260 /$ jemds $/ 2018 / 123$

(c) (i) $\ominus$ serum creatinine and serum electrolytes were within normal limits. $(2,3,4,5)$ On imaging, $x$-ray abdomen showed opacity in the whole lower abdomen and multiple dilated bowel loops.

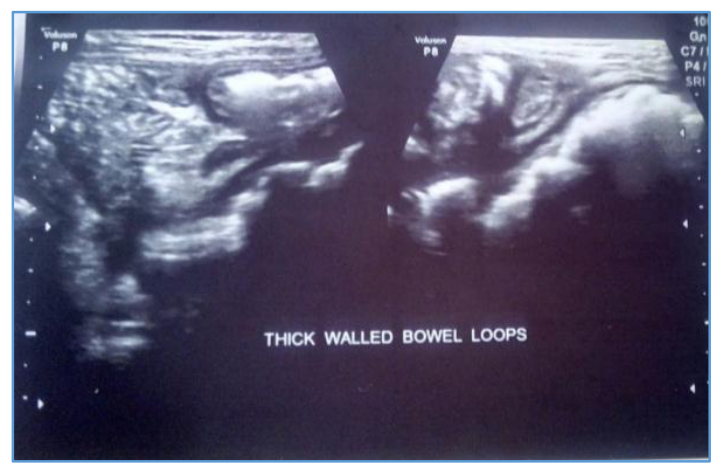

Multiple thick walled hypoechoic to echogenic bowel segment with large amount of gas shadows and few dilated bowel loops.

CT scan of the abdomen showed multiple hyperdense opacities with central hypodense area diffusely scattered in the whole abdomen, predominantly in small bowel loop, suggestive of faecolith and large amount of foreign bodies, suggestive of small bowel obstruction.

\section{DISCUSSION OF MANAGEMENT}

The patient underwent emergency exploratory with the finding of dense encasement of whole small bowel and large bowel suggestive of abdominal cocoon. On meticulous adhesiolysis, highly distended terminal ileum and caecum were found.(6,7) Palpation of the bowel showed discrete, small, hard foreign bodies in lumen of small bowel which were extracted manually. These marbles weighted about half a kilogram. Resection of part of terminal ileum and ascending colon done with fashioning of double barrel stoma. Postoperative course was eventful and the patients died after one day.

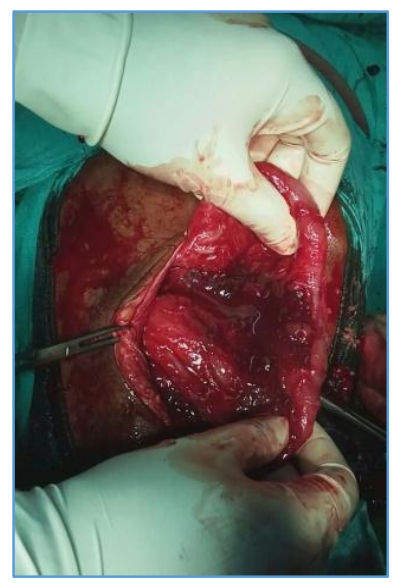

Incision shows bowel with Dense Adhesion 


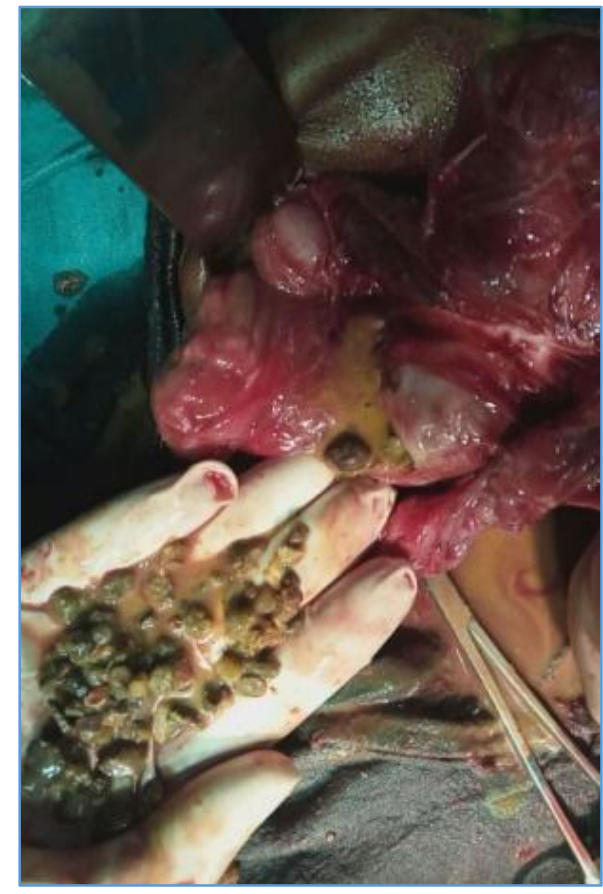

Perforated bowel with Stone

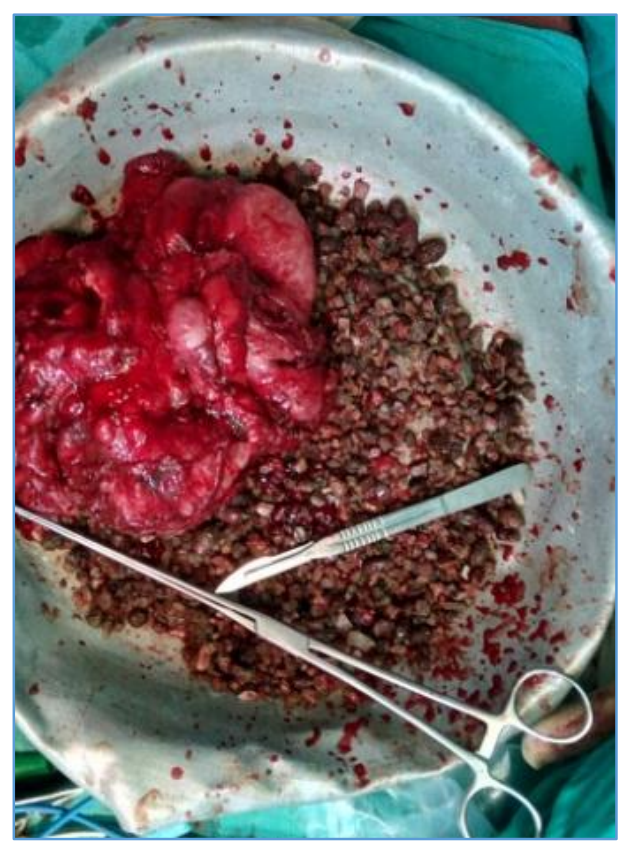

Resected bowel with Stone

\section{FINAL DIAGNOSIS}

In our case report cause of partial bowel obstruction is due to accumulation of large amount of small foreign bodies towards ileum and caecum. Ingestion of foreign body may be seen at any age. Mostly, it is accidental. 98\% (peak incidence) of foreign body ingestion occurs between 6 months and 3 yrs. of age.
$40 \%$ of reported case of foreign body occurs without recognition of parents. Coins are the most commonly ingested foreign body. Although, $80 \%$ to $90 \%$ of swallowed foreign body will pass spontaneously, there is a definite predilection for swallowed foreign body to become stuck at the level of cricopharyngeus and just below it or at the oesophagogastric junction. $10 \%$ - 20\% requires endoscopic removal and only less than $1 \%$ need surgical intervention. $(8,9,10)$

In our case report, foreign body are concrete marbles which passes through stomach and present in terminal ileum and caecum. So, this presented with late complications, bilious vomiting, abdominal distension, constipation and subacute intestinal obstruction. In our case, surgical intervention was done in the form of laparotomy. Foreign body is a common public health problem, especially in children.(11,12)

\section{REFERENCES}

[1] Wright CC, Closson FT. Updates in pediatric gastrointestinal foreign bodies. Pediatr Clin North Am 2013;60(5):1221-39.

[2] Uyemura MC. Foreign body ingestion in children. Am Fam Physician 2005;72(2):287-91.

[3] Gregori D, Scarinzi C, Morra B, et al. Ingested foreign bodies causing complications and requiring hospitalization in European children: results from the ESFBI study. Pediatr Int 2010;52(1):26-32.

[4] Walker WA, Goulet O, Kleinman RE, et al. Pediatric Gastrointestinal disease. $4^{\text {th }}$ edn. Ontario: BC Decker 2004; pp. 1691-2.

[5] Kay M, Wyllie R. Pediatric foreign bodies and their management. Curr Gastroenterol Rep 2005;7(3):212-8.

[6] Waltzman ML, Baskin M, Wypij D, et al. A randomized clinical trial of the management of esophageal coins in children. Pediatrics 2005;116(3):614-9.

[7] Wong KK, Fang CX, Tam PK. Selective upper endoscopy for foreign body ingestion in children: an evaluation of management protocol after 282 cases. J Pediatr Surg 2006;41(12):2016-8.

[8] Schwartz GF, Polsky HS. Ingested foreign bodies of the gastrointestinal tract. Am Surg 1976;42(4):236-8.

[9] Smith MT, Wong RK. Foreign bodies. Gastrointest Endosc Clin N Am 2007;17(2):361-82.

[10] Balci AE, Eren S, Eren MN. Esophageal foreign bodies under cricopharyngeal level in children: an analysis of 1116 cases. Interact Cardiovasc Thorac Surg 2004;3(1):14-8.

[11] Kay M, Wyllie R. Techniques of foreign body removal in infants and children. Tech Gastrointest Endosc 2002;4(4):188-95.

[12] Sugawa C, Ono $H$, Taleb $M$, et al. Endoscopic management of foreign bodies in the upper gastrointestinal tract: a review. World J Gastrointest Endosc 2014;6(10):475-81. 